\title{
Preparedness for mass gatherings: rescue and emergency medical services' workloads during mass gathering events
}

Anssi Koski 1,2* (D), Jukka Pappinen ${ }^{3}$, Anne Kouvonen ${ }^{4,5}$ and Hilla Nordquist ${ }^{1,2,4}$

\begin{abstract}
Background: Mass gathering (MG) events may cause delayed emergency responses via various mechanisms and strain the resources of local emergency services. Therefore, preparedness, including adequate pre-planning and sufficient resourcing during MG events, is vital. The aim of this retrospective register study was to investigate the impact of MG events on the workload of rescue and emergency medical service (EMS) personnel during events to enable more precise and sufficient deployment of these authorities' operative resources.
\end{abstract}

Methods: The data from Finland covered of 25,124 EMS and rescue service missions during a three-year period (2015-2017), including data from nine MG events and reference material for the same weekdays two weeks before and after the event. The data were analysed through statistical and geospatial analyses.

Results: Our findings showed that missions increased in most events included in this study. Analysis of the missions' reasons showed that the categories of violence, traffic accidents and other accidents and injuries increased during events, with violence-related missions showing the highest relative risk (RR 1.87, 95\% Cl 1.43-2.44). In the four-grade (A-D) urgency grading, the analysis showed an increase in category $C$ missions and a decrease in non-urgent category D missions. The analysis indicated an increase in missions during the evening and night-time. The geospatial analysis revealed dense hotspots of missions in the vicinity of the event area.

Conclusion: The workload for EMS and rescue service personnel increases during MG events. Most of the increase is allocated to EMS staff, peaking in evening and night hours. The geospatial analysis showed hotspots of missions on the outskirts of the actual event area during events; thus, the workload can also increase for those authority resources that are not directly allocated to the event. Detailed information regarding workloads is valuable for the authorities that are responsible for resource planning and preparedness for MG events. Replicating the study internationally would improve the methodology for the future.

Keywords: Preparedness, Mass gatherings, Emergency medical services, Rescue service, Event organizers

\section{Introduction}

Mass gathering (MG) events may increase the workloads of local emergency services and healthcare facilities [1-4]. The World Health Organization criteria for

*Correspondence: anssi.koski@helsinki.fi

1 South-Eastern Finland University of Applied Sciences, 48220 Kotka, Finland

Full list of author information is available at the end of the article
MGs is that they are organized or spontaneous events where attendance is sufficient to strain local planning and response resources [5]. According to earlier studies, an increased workload during MG events especially affects emergency medical services (EMS) $[1,6-8]$. The workload for rescue services seems to be concentrated mainly in the pre-event phase, focusing on the emergency planning process [6]. Previous research has shown that MG environmental characteristics that influence workload original author(s) and the source, provide a link to the Creative Commons licence, and indicate if changes were made. The images or other third party material in this article are included in the article's Creative Commons licence, unless indicated otherwise in a credit line to the material. If material is not included in the article's Creative Commons licence and your intended use is not permitted by statutory regulation or exceeds the permitted use, you will need to obtain permission directly from the copyright holder. To view a copy of this licence, visit http://creativecommons.org/licenses/by/4.0/. The Creative Commons Public Domain Dedication waiver (http://creativecommons.org/publicdomain/zero/1.0/) applies to the data made available in this article, unless otherwise stated in a credit line to the data. 
include on-site medical care [9-19], the event type, location and duration $[20,21]$ and the weather conditions [22, 23]. In addition, participant-related factors, such as drug and alcohol use and crowd demographics and behaviour, can have an impact on medical workload $[3,13,15,21$, $24,25]$.

An ability to predict workload provides valuable information for EMS and rescue service resource planning during MG events. In prior studies, different approaches, including retrospective [2, 3, 17, 20, 22-24, 26-31] and predictive [14, 21,32-35] investigations of events, have been used. Overall, the previous literature on utilizing data on MGs is strongly dominated by healthcare. In this study, we included both EMS and rescue services and utilized geospatial analysis, thus bringing a new approach to this research area. Accurate information about workload during an event enables more precise resource and preparedness planning.

MG events in Finland occur mainly during summer months and across the country [36]. The population and major cities of Finland are highly concentrated in the southern and western parts of the country [37]. A large MG event in a relatively small town may cause a significant burden on the local EMS and rescue services.

The aim of this study was to investigate EMS and rescue service workloads during MG events. The specific objectives were to examine (1) if EMS and rescue service workload increases during MGs; (2) how time of day affects workload during the event; and (3) what the geospatial distribution of the workload during the event is.

\section{Methods}

\section{Study setting}

In this study, the workload of EMS and rescue services was investigated for nine MG events by comparing the mission data during these events to the reference data of the same weekdays two weeks before and after the event.

\section{Data collection}

The material used in the present study consists of Emergency Response Centre mission (EMS and rescue service) data from a three-year period (2015-2017) during nine MG events in Finland. The data contain event data and reference mission data from the same weekdays as the event as well as two weeks before and two weeks after the event. The time period included 97 event days and 388 reference days. The MG events selected for this study were events held in various sized settlements, including the biggest cities-Helsinki, Tampere, Oulu and Turkuand smaller rural towns, i.e. Pori, Joensuu, Seinäjoki, Kotka and Jämsä. The events took place in different parts of the country, apart from the north. The duration of the events ranged from two to nine days.

\section{Eligibility criteria}

The selection criteria for the MGs were summer as the time of the year, an outdoors venue and a live music event.

\section{Data sources, measurements and analysis}

The data contain city/town, type of mission, urgency, date, time and coordinate information for each EMS or rescue service mission. EMS transfer missions between healthcare facilities were excluded. The data included 25,124 individual missions, of which 23,957 were EMS missions and 1167 were rescue service missions. EMS units respond to, for example, in traffic accidents and house fires, despite the responsible authority in command being the rescue service. Thus, the data were analysed in five mission categories that included both authorities: other accident/injury, traffic accident, violence, cardiac arrest and other diseases.

Missions are categorized according to their urgency. The urgency category affects the response to a specific mission. In the initial response, most high-risk missions include additional resources, such as first responders or helicopter-based emergency medical service (HEMS) units in addition to conventional EMS units. The urgency category also determines the initial response and the type and number of units of the rescue service. The urgency categories (ABCD) in EMS missions are defined in Finnish legislation under $\mathbb{S} 6$ of the Social and Health Ministry decree on Emergency Medical Services 585/2017 (Table 1).

The statistical analysis was conducted using Excel software, and the geospatial analysis was carried out with ArcGIS Pro for Windows, version 2.6.2 (Esri Inc.). Geospatial analysis combines coordinate data and geographical information in a visual display format. The mission information was processed on a map background with ArcGIS and displayed as heat maps, which indicate call density hotspots in the area. In the statistical analysis, relative risk (RR) with 95\% confidence intervals (CIs) was calculated for the event locations, mission causes and urgency categories. P-values were calculated from the RRs to determine the statistical significance of the findings.

\section{Results}

Categorized and classified by the responsible authority, the vast majority of the combined missions during the events $(n=5949)$ were EMS missions $(n=5617)$, and the rest were rescue service missions $(n=332)$. The operative workload of the EMS and the rescue services during MG events increased in 8 out of 9 events included in this study, and the RR was above 1 for all 
events, except those that took place in the capital city, Helsinki. The workload increase was statistically significant in 6 out of 9 events (Table 1). The event-specific investigation showed that the RR for an event was lowest (RR 0.97, 95\% CI 0.77-1.22) in Helsinki (with the largest population) and highest in the town of Jämsä (with the smallest population) in Central Finland (RR 1.75, 95\% CI 1.30-2.37) (Table 2). The total missions per day in the reference data of the same geographical (spatial) area were compared with the mission count during the event.
The analysis of the data by cause of the mission showed statistically significant increases in violence-related missions and the traffic accident and other accident/injury categories (Table 3). The RR was highest in the violence category (RR 1.87, 95\% CI 1.43-2.44) and lowest in the other disease category (RR 1.13, 95\% CI 0.90-1.41). The 95\% CI was wider in cardiac arrests, as category n was relatively small (Table 3 ).

The analysis of the mission urgency categories showed that category $\mathrm{C}$ missions increased statistically significantly during the events, with an average of 7.13

Table 1 Dispatch criteria

\begin{tabular}{|c|c|c|c|c|c|}
\hline \multirow{2}{*}{$\begin{array}{l}\text { Mission } \\
\text { category }\end{array}$} & \multirow[t]{2}{*}{ Response } & \multicolumn{2}{|l|}{ Level of risk } & \multicolumn{2}{|l|}{ Situational assessment } \\
\hline & & EMS & Rescue & EMS & Rescue \\
\hline$A$ & Lights and sirens & High risk & High risk & $\begin{array}{l}\text { Immediate threat for vital life } \\
\text { functions }\end{array}$ & $\begin{array}{l}\text { Immediate saving of a person or } \\
\text { environment of great value of } \\
\text { assets }\end{array}$ \\
\hline B & Lights and sirens & Propable high risk & Propable high risk & $\begin{array}{l}\text { No certanity of immediate threat } \\
\text { for vital life functions }\end{array}$ & $\begin{array}{l}\text { Unconfirmed possible lifesav- } \\
\text { ing or major additional damage } \\
\text { preventing }\end{array}$ \\
\hline C & Urgent & Require swift assessment & Static accident & Stable vital life functions & $\begin{array}{l}\text { Assessed not to result immediate } \\
\text { additional damage }\end{array}$ \\
\hline D & Non-urgent & Require assessment & No immediate action & Stable vital life functions & $\begin{array}{l}\text { Response in approppriate or } \\
\text { agreed date }\end{array}$ \\
\hline
\end{tabular}

Table 2 Event-specific workload analysis

\begin{tabular}{|c|c|c|c|c|c|c|c|c|c|}
\hline $\begin{array}{l}\text { Event location } \\
\text { (inhabitants) }\end{array}$ & Event $\mathrm{n}$ & Reference $n$ & n/day event & $\mathrm{n} /$ day reference & $\begin{array}{l}\mathrm{n} \pm \text { change/ } \\
\text { day during } \\
\text { event }\end{array}$ & $95 \% \mathrm{Cl}$ upper & $95 \% \mathrm{Cl}$ lower & RR & Sig. \\
\hline Helsinki (656 250) & 1746 & 7180 & 194.0 & 199.44 & -5.44 & 1.22 & 0.77 & 0.97 & 0.823 \\
\hline Oulu (207 717) & 600 & 1821 & 100 & 75.88 & +24.12 & 1.68 & 1.04 & 1.32 & $<0.05$ \\
\hline Tampere (241 672) & 527 & 1896 & 87.83 & 79.00 & +8.83 & 1.42 & 0.87 & 1.11 & 0.399 \\
\hline Turku (194 244) & 781 & 2365 & 86.78 & 65.69 & $+21,09$ & 1.67 & 1.04 & 1.32 & $<0.05$ \\
\hline Joensuu (76 833) & 415 & 1090 & 46.11 & 30.28 & +15.83 & 1.95 & 1.19 & 1.52 & $<0.01$ \\
\hline Pori (83 676) & 1063 & 2584 & 39.37 & 23.90 & +15.47 & 2.08 & 1.30 & 1.65 & $<0.01$ \\
\hline Kotka (51 603) & 422 & 1116 & 32.46 & 21.46 & +11 & 1.94 & 1.18 & 1.51 & $<0.01$ \\
\hline Seinäjoki (64 335) & 259 & 813 & 28.78 & 22.58 & +6.2 & 1.66 & 0.98 & 1.27 & 0.070 \\
\hline Jämsä (19 894) & 136 & 310 & 15.11 & 8.61 & +6.5 & 2.37 & 1.30 & 1.75 & $<0.01$ \\
\hline
\end{tabular}

Table 3 Mission cause analysis

\begin{tabular}{|c|c|c|c|c|c|c|c|c|c|}
\hline Cause of mission & Event $\mathrm{n}$ & Reference $n$ & $n /$ day event & $\mathrm{n} /$ day reference & $\begin{array}{l}\mathrm{n} \pm \text { change/ } \\
\text { day during } \\
\text { event }\end{array}$ & $95 \% \mathrm{Cl}$ upper & 95\% Cl lower & RR & Sig. \\
\hline Other accident / injury & 1760 & 5018 & 18.14 & 12.93 & +5.21 & 1.76 & 1.12 & 1.40 & $<0.01$ \\
\hline Traffic accident & 288 & 702 & 2.97 & 1.81 & +1.16 & 2.13 & 1.26 & 1.64 & $<0.01$ \\
\hline Violence & 252 & 540 & 2.60 & 1.39 & +1.21 & 2.44 & 1.43 & 1.87 & $<0.01$ \\
\hline Cardiac arrest & 56 & 157 & 0.58 & 0.40 & +0.17 & 2.08 & 0.98 & 1.43 & 0.065 \\
\hline Other diseases & 3593 & 12,758 & 37.04 & 32.88 & +4.16 & 1.41 & 0.90 & 1.13 & 0.305 \\
\hline
\end{tabular}


additional missions per event day (Table 3). The RR analysis of the mission urgency categories showed a RR of 1.25 (95\% CI 0.97-1.61) for category A, 1.22 (95\% CI $0.97-1.54$ ) for category B and 1.33 (95\% CI 1.05-1.66) for category C. The RR for category D was 0.83 (95\% CI 0.66-1.04) (Table 4).

We also investigated mission dispersion by time of day. There was no statistically significant increase in workload during events between 08:00 and 20:00, whereas the RR for 20:00-08:00 h was 1.39 (95\% CI 1.11-1.75). Our findings thus indicate that the workload increase during events for EMS and rescue services occurred especially in the evening and at night. The geospatial analysis supported this finding.

\section{Geospatial analysis}

The geospatial investigation of the workload during events indicated that the events created dense hotspots of missions in the vicinity of the event areas in addition to common hotspots such as city centres that appeared also in the reference data. This density hotspot is clearly visible in an example illustration from event in Turku (Fig. 1).

In the reference data, the mission density hotspot is only visible in the city centre area, and the event area location is clear. A supplementary mission density animation of an event in Turku shows that missions peaked in the vicinity of the event area, especially during late hours. In addition, missions seemed to occur in the route between the event area and the city centre, near and after the closing time of the event area (Additional file 1: Animation).

\section{Discussion}

Our findings show that the workloads of both the EMS and the rescue services increased during MG events, peaking especially in the evening and at night. The results showed a statistically significant increase in violence-related missions and the traffic accident and other accident/injury categories during the MG events. According to the urgency categories, urgent C-level missions increased the RR and non-urgent category D missions decreased the RR during the events. This affects the initial response efficiency, as urgent missions have shorter response time windows than non-urgent missions. The geospatial analysis revealed hotspots of EMS missions in the vicinity of the event area, as well as an increase in missions between the venue and the city centre. This study revealed information about EMS and rescue services' workloads during MGs in a completely new level of detail.

Our results confirm previous findings that showed that most missions during MG events are allocated to EMS, whereas the increase in the rescue service workload is minor $[1,6]$. Furthermore, previous studies support the finding that MG events impact local healthcare resources $[2,3,31,38]$. According to our findings, the increase in missions is higher in rural areas than in big cities. This is another aspect that requires attention when considering the need for preparedness, as local resources are typically scaled for their usual population. In this study, the highest increase in workload occurred in the location in which the population was the smallest. As resources in smaller settlements may be more easily overwhelmed than in bigger cities, event organizers' own levels of preparedness need special focus and attention. This conclusion is supported by previous studies indicating that austere environments also create a need for stronger preparedness for event organizers $[6,30]$.

A closer investigation of mission causes showed that the RR was highest for violence-related missions. Traffic accidents and other accidents and injuries, including intoxications, also increased. Previous studies have shown that the presence of alcohol and drugs increases the need for medical care [3, 13, 15, 20, 21, 24, 32, 33], whereas on-site medical care [9-13, 31] and alcohol sobering-up facilities [18] decrease the need for outside medical care. A recent study suggested, with an $86 \%$ consensus, that in the largest and highest-risk events, event organizers should be required to arrange on-site professional medical services and limit volunteer-based care. However, the expert board did not reach consensus about the event's professional healthcare operator also participating in the treatment of emergency patients. In other words, treatment of major/life-threatening injuries should be performed by the EMS despite the level

Table 4 Mission urgency analysis

\begin{tabular}{|c|c|c|c|c|c|c|c|c|c|}
\hline $\begin{array}{l}\text { Mission } \\
\text { urgency } \\
\text { category }\end{array}$ & Event $n$ & Reference $\mathrm{n}$ & n/day event & $\mathrm{n} /$ day reference & $\begin{array}{l}\mathbf{n} \pm \text { change/day } \\
\text { during event }\end{array}$ & $95 \% \mathrm{Cl}$ upper & $95 \% \mathrm{Cl}$ lower & $\mathbf{R R}$ & Sig. \\
\hline A & 345 & 1102 & 3.56 & 2.84 & +0.72 & 1.61 & 0.97 & 1.25 & 0.081 \\
\hline B & 1385 & 4525 & 14.28 & 11.66 & +2.62 & 1.54 & 0.97 & 1.22 & 0.085 \\
\hline C & 2816 & 8498 & 29.03 & 21.90 & +7.13 & 1.66 & 1.06 & 1.33 & $<0.05$ \\
\hline D & 1042 & 5042 & 10.74 & 12.99 & -2.25 & 1.04 & 0.66 & 0.83 & 0.108 \\
\hline
\end{tabular}




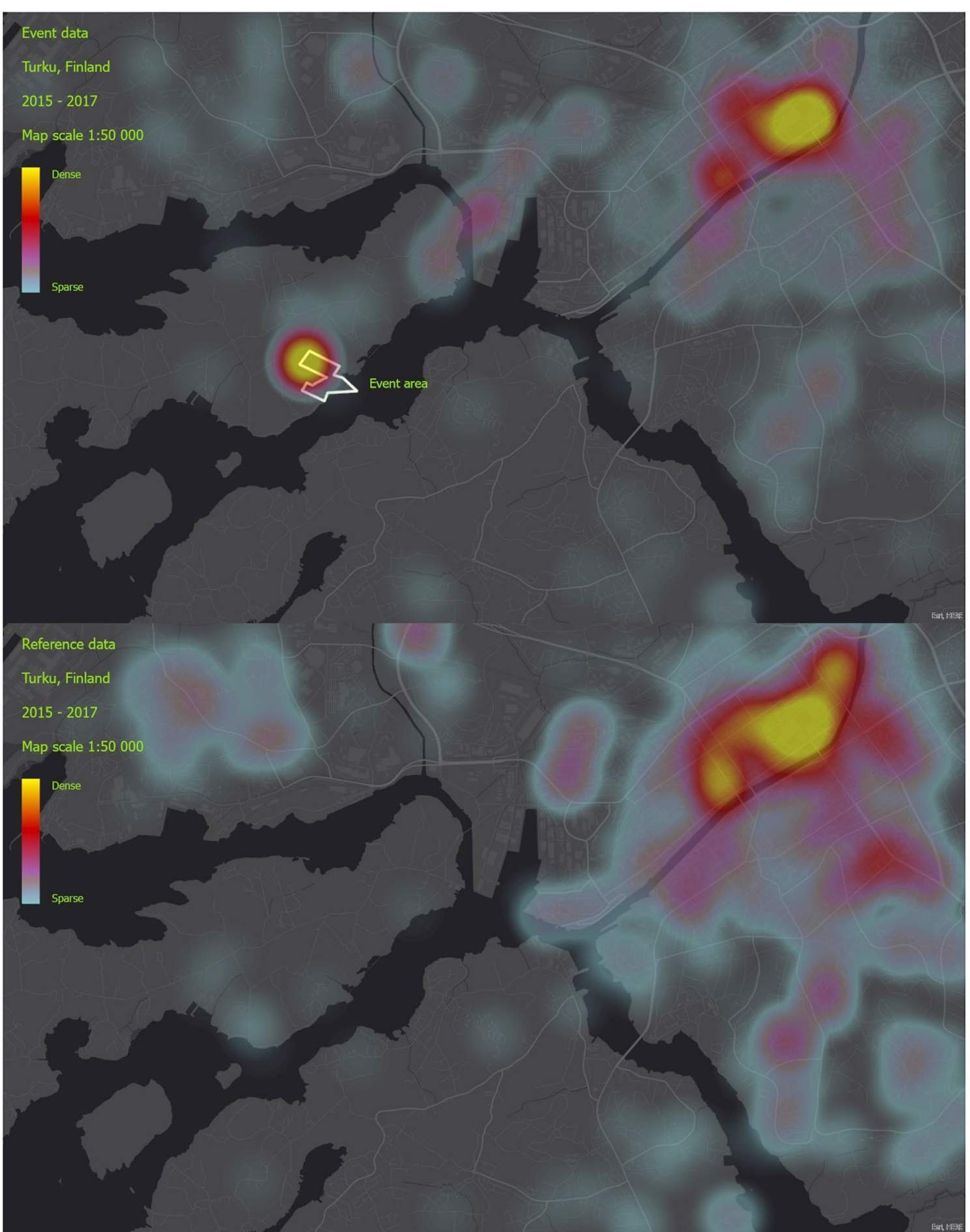

Fig. 1 Event/reference data heat map, City of Turku, Finland

of on-site medical care [39]. An increased workload for police is deducible from the high increase in violencerelated missions; this has also been recognized in previous studies $[1,4]$.
The geospatial analysis revealed dense concentrations of EMS missions in the outskirts of the event areas. These hotspots were more visible in the venues outside city centres, as there was also a concentration of missions in 
the reference data. In addition, in some cases, there was an increase in missions in the geographical area between the event area and the city centre hotspots. Our findings also showed that the workloads peaked at certain times of day, especially at night-time in the vicinity of the event area. According to previous studies, authorities need to pre-allocate additional resources for MG events, but this preparedness should concentrate on the outskirts of the event area $[6,39]$.

\section{Strengths and limitations}

Using the mission data, we were able to obtain comprehensive information on the EMS and rescue service workloads during MG events. The mission volume, profiles and timestamps were accurate numeric information, which gave more precise results than prior qualitative studies.

Our study included only two of the three major emergency services authorities because police mission data with no EMS participation was not included in the study due to data availability and confidentiality. Despite this limitation, our results indicated an increase in violencerelated missions. Investigation of police forces' workloads could thus give additional valuable information for better overall emergency services preparedness. Unit-specific information was unavailable in our data; therefore, the selection of the responsible authority between the EMS and rescue services was done based on the mission code. In Finland, both EMS and rescue services occasionally respond to each other's missions. Such mission types are for different types of accidents. In some mission types, such as house fires with no casualties, EMS are dispatched in a work safety role. Rescue services may be used in medical emergencies in the first responder role. Many EMS and rescue service mission types involve both authorities. Therefore, in the general analysis, all missions including both authorities were included in the five-category classification.

The results of this study provide detailed information on the EMS and rescue service workload during MG events. This information can be utilized in the preparedness and resource planning stages of MG events. The use of statistical and geospatial methods enabled the analysis of accurate and adequate resource deployment in the correct geographical locations in the right time window. This effective and sufficient resource deployment enforces the level of service during MG events and may improve opportunities to respond to emergencies.

Outcome measures, such as delay in routine missions and mortality and morbidity during the event, were not included in this study, which may be considered a limitation for the importance of this study. In addition, X-percentage (no transportation to hospital with ambulance) would give valuable and more detailed information on the mission profiles. However, the dataset used in this study contained only city, dispatch time, mission code and GIS information.

\section{Conclusions}

According to this study, EMS and rescue service workloads increase during MG events. The increase focuses mostly on EMS and peaks especially in the evening and at night. The geospatial analysis showed unexpected additional hotspots outside MG event areas during the events. This study is relevant for future similar validation studies internationally.

\section{Abbreviations \\ MG: Mass gathering; EMS: Emergency medical services; RR: Relative risk; Cl: Confidence interval.}

\section{Supplementary Information}

The online version contains supplementary material available at https://doi. org/10.1186/s13049-022-01003-7.

Additional file 1. 24-h workload animation.

\section{Acknowledgements \\ The authors wish to thank the Fire Protection Fund for enabling the research and development of preparedness for mass gatherings in Finland by funding a research and development project that included this work.}

\section{Authors' contributions}

AKos was a major contributor to the conception and writing of the manuscript and contributed to the interpretation of the data. JP, AKou and HN made substantial contributions to the conception, design, analysis and interpretation of the data and writing the manuscript. All the authors have read and approved the final manuscript.

\section{Funding}

The Fire Protection Fund (grant number SM1827443) and South-Eastern Finland University of Applied Sciences supported this work.

Availability of data and materials

Data are available upon reasonable request from JP.

\section{Declarations}

Ethics approval and consent to participate

No patient data were used in this study, so Medical Ethics Committee approval was not required.

Consent for publication

Not applicable.

Competing interests

The authors declare that they have no competing interests.

\section{Author details}

${ }^{1}$ South-Eastern Finland University of Applied Sciences, 48220 Kotka, Finland. ${ }^{2}$ Faculty of Medicine, University of Helsinki, 00014 Helsinki, Finland. ${ }^{3}$ Faculty of Health Sciences, University of Eastern Finland, PO Box 1627, 70211 Kuopio, Finland. ${ }^{4}$ Faculty of Social Sciences, University of Helsinki, 00014 Helsinki, Finland. ${ }^{5}$ Centre for Public Health, Queen's University Belfast, Belfast BT12 6BA, UK. 
Received: 29 October 2021 Accepted: 19 February 2022

Published online: 05 March 2022

\section{References}

1. Zeitz K, Bolton S, Dippy SSR, Dowling Y, Francis L, Thorne J, Butler T, Zeitz C. Measuring emergency services workloads at mass gathering events. Aust J Emerg Manag. 2007;22(3):23-30.

2. Ranse J, Hutton A, Keene T, Lenson S, Luther M, Bost N, Johnston A, Crilly J, Cannon M, Jones N, Hayes C, Burke B. Health service impact from mass gatherings: a systematic literature review. Prehosp Disaster Med. 2017:32(1):1-7.

3. Chhabra N, Gimbar RP, Walla LM, Thompson TM. Emergency department patient burden from an electronic dance music festival. J Emerg Med. 2018;54(4):435

4. Saari K. Crowd situations and their policing from the perspective of finnish police officers-a case study of finnish police knowledge. J Scand Stud Criminol Crime Prev. 2009;10(2):102-19.

5. WADEM. World Association of Disaster and Emergency Medicine-about mass gatherings. 2022. https://wadem.org/sigs/mass-gathering/.

6. Koski A, Kouvonen A, Sumanen H. Preparedness for mass gatherings: factors to consider according to the rescue authorities. Int J Environ Res Public Health. 2020;17(4):1361.

7. Arbon P. Planning medical coverage for mass gatherings in Australia: what we currently know. J Emerg Nurs. 2005;31(4):346-530.

8. Sabra JP, Cabañas JG, Bedolla J, Borgmann S, Hawley J, Craven K, Brown C, Ziebell C, Olvey S. Medical support at a large-scale motorsports massgathering event: the inaugural formula one united states grand prix in Austin, Texas. Prehosp Disaster Med. 2014;29(04):1-7.

9. Grange JT, Baumann GW, Vaezazizi R. On-site physicians reduce ambulance transports at mass gatherings. Prehosp Emerg Care. 2003:7(3):322-6.

10. Feldman MJ, Lukins JL, Verbeek PR, Burgess RJ, Schwartz B. Use of treat-and-release medical directives for paramedics at a mass gathering. Prehosp Emerg Care. 2005;9(2):213-7.

11. Lukins JL, Feldman MJ, Summers JA, Verbeek PR. A Paramedic-staffed medical rehydration unit at a mass gathering. Prehosp Emerg Care. 2004;8(4):411-6.

12. Kemp A. Mass-gathering events: the role of advanced nurse practitioners in reducing referrals to local health care agencies. Prehosp Disaster Med. 2015:1(1):1-6.

13. Krul J, Sanou B, Swart EL, Girbes ARJ. Medical care at mass gatherings: emergency medical services at large-scale rave events. Prehosp Disaster Med. 2012;27(1):71-4.

14. Smith WP, Tuffin H, Stratton SJ, Wallis LA. Validation of a modified medical resource model for mass gatherings. Prehosp Disaster Med. 2013;28(01):1-7.

15. Wood DM, Beaumont PO, May D, Dargan PI. Recreational drug use presentations during a large outdoor festival event: reduction in hospital emergency department transfer where medical physicians are present. J Subst Use. 2010;15(6):434-41.

16. McQueen C, Davies C. Open Access Emergency Medicine Health care in a unique setting: applying emergency medicine at music festivals. Open Access Emerg Med. 2012;4:69.

17. Turris SA, Callaghan CW, Rabb H, Munn MB, Lund A. On the way out: an analysis of patient transfers from four large-scale north American music festivals over two years. Prehosp Disaster Med. 2019;34(1):72.

18. Castro-Marin F, Maher SA, Navarro T, Nuño T, Whitney J, McDonald A, Razo A, Marcuzzo C, Chick R, Gaither J. Impact of a mass gathering alcohol sobering facility on emergency resources. Prehosp Emerg Care. 2018;22(3):1-6.

19. Schwartz B, Nafziger S, Milsten A, Luk J, Yancey A. Mass gathering medical care: resource document for the national association of EMS physicians position statement. Prehosp Emerg Care. 2015;19(4):559.

20. Moore R, Williamson K, Sochor M, Brady WJ. Large-event medicineevent characteristics impacting medical need. Am J Emerg Med. 2011;29(9):1217-21

21. Locoh-Donou S, Yan G, Berry T, O'Connor R, Sochor M, Charlton N, Brady W. Mass gathering medicine: event factors predicting patient presentation rates. Inter Emerg Med. 2016;11(5):745.
22. Baird M, O'Connor R, Williamsson A, Sojka B, Alibertis K. The impact of warm weather on mass event medical need: a review of the literature. Am J Emerg Med. 2010:28(2):224-9.

23. Perron A, Brady W, Custalow C, Johnson D. Association of heat index and patient volume at a mass gathering event. Prehosp Emerg Care. 2005;9(1):49-52.

24. Hutton A, Ranse J, Verdonk N, Ullah S, Arbon P. Understanding the characteristics of patient presentations of young people at outdoor music festivals. Prehosp Disaster Med. 2014;29(2):1-7.

25. Hutton A, Ranse J, Zimmerman PA. Rethinking mass-gathering domains for understanding patient presentations: a discussion paper. Prehosp Disaster Med. 2020;2020:20-3.

26. Zeitz KM, Schneider DPA, Jarrett D, Zeitz CJ. Mass gathering events: retrospective analysis of patient presentations over seven years. Prehosp Disaster Med. 2002;17(3):147-50.

27. Locoh-Donou S, Guofen Y, Welcher M, Berry T, O'Connor RE, Brady WJ. Mass-gathering medicine: a descriptive analysis of a range of massgathering event types. Am J Emerg Med. 2013;31(5):843.

28. Milsten AM, Seaman KG, Liu P, Bissell RA, Maguire BJ. Variables influencing medical usage rates, injury patterns, and levels of care for mass gatherings. Prehosp Disaster Med. 2003;18(4):334-46.

29. Milsten AM, Maguire BJ, Bissell RA, Seaman KG. Mass-gathering medical care: a review of the literature. Prehosp Disaster Med. 2002;18(4):334-46.

30. Bledsoe B, Songer P, Buchanan K, Westin J, Hodnick R, Gorosh L. Burning man 2011: mass gathering medical care in an austere environment. Prehosp Emerg Care. 2012;16(4):469-76.

31. Meites E, Brown JF. Ambulance need at mass gatherings. Prehosp Disaster Med. 2010;25(6):511-4

32. Hartman N, Williamson A, Sojka B, Alibertis K, Sidebottom M, Berry T, Hamm J, O'Connor R, Brady J. Predicting resource use at mass gatherings using a simplified stratification scoring model. Am J Emerg Med. 2009;27(3):337-43.

33. Arbon P, Bridgewater FHG, Smith C. Mass gathering medicine: a predictive model for patient presentation and transport rates. Prehosp Disaster Med. 2001;16(3):150-8.

34. Zeitz KM, Zeitz CJ, Arbon P. Forecasting medical work at mass-gathering events: predictive model versus retrospective review. Prehosp Disaster Med. 2005;20(3):164-8.

35. Spaepen K, Haenen WAP, Hubloue I. The development of PRIMA-a Belgian prediction model for patient encounters at mass gatherings. Prehosp Disaster Med. 2020;35(5):1-7.

36. Finland festivals. Festivals in Finland. 2021. https:/festivals.fi/en/festivals/.

37. Official Statistics of Finland (OSF). OSF population structure [Internet]. Population structure [e-publication]. ISSN 1797-5395. 2019 [cited 2021 Aug 23] http://www.stat.fi/til/vaerak/index_en.html.

38. Arbon P. Mass-gathering medicine: a review of the evidence and future directions for research. Prehosp Disaster Med. 2007;22(2):131-5.

39. Koski A, Kouvonen A, Nordquist H. Preparedness for mass gatherings: planning elements identified through the Delphi process. Int J Disaster Risk Reduct. 2021;61:102368.

\section{Publisher's Note}

Springer Nature remains neutral with regard to jurisdictional claims in published maps and institutional affiliations. 